\title{
Phonetic features of Chinese in teaching students at the Institute of languages and culture of the peoples of North- Eastern of the Russian Federation
}

\author{
Amalia Prokopeva ${ }^{1, *}$ and Galina Zakharova ${ }^{l}$ \\ ${ }^{1}$ North-Eastern federal university in Yakutsk, Institute of Languages and Culture of the Peoples of the North-East of the Russian \\ Federation, 677027, Republic of Sakha (Yakutia), Russia
}

\begin{abstract}
Annotation. The purpose of the article is to develop students' personal qualities, as well as the formation of universal, general professional and professional competencies in accordance with the requirements of the Federal State Educational Standard of Higher Education in the direction of 44.03.05 Teacher Education (two training profiles). Native language (Yakut) and the literature and the foreign language (Chinese) training. The task is to provide the highly qualified teachers with a high level of professional and social competence, proficient in the specifics of intercultural communication and foreign languages, in particular Chinese, through innovative technologies, methods, and creative practices.
\end{abstract}

\section{Introduction}

Research methods: comparative analysis of the content of textbooks on foreign languages and organizational and pedagogical conditions in national schools of the Republic of Sakha (Yakutia).

Achieved results: in 2020 for the implementation of an innovative methodology for the study of Yakut literature is protected with excellent marks a graduation qualification work of I. Rozhina. She won prizes in university and regional scientific and practical conferences and conducted regional seminars on the problems of digitalization of the educational process at school. In addition, 4 bachelor's graduation works were defended with excellent marks in June 2021.

Currently, the Chinese language firmly occupies its rightful place in the linguistic picture of the world. Along with other languages, it plays a very positive role in the development of the economy, culture, and technology in the Russian Federation. The head of the Republic of Sakha (Yakutia) Aisen Nikolaev said at the V International Forum "Arctic - Territory of Dialogue" that China and Russia have great prospects for cooperation in the Arctic. He also mentioned that China has a huge market and is an ideal business partner; its economy is growing at an impressive pace.

Based on this, new challenges, and requirements for educational programs of a higher educational institution arise. Today the university acts as a navigator of education, science and interaction with society. In 2016, the Department of teaching methods of the Yakut language, literature and national culture initiated the opening of a new educational program in the direction of 44.03.05 Teacher Education (two training profiles). Native language (Yakut) and the literature and the foreign language (Chinese) training.

The educational program is developed in accordance with the Federal State Educational Standard. This program is the main educational practice-oriented program of the bachelor's level of full-time education, which assumes the availability of both budgetary and paid places. The language of instruction is Russian, Yakut, Chinese. For admission, they pass the Unified State Exam results in the Russian language, social studies, and a creative competition. The opening of the program is due to the priority areas of development of the North-Eastern Federal University named after M.K. Ammosov of the Republic of Sakha (Yakutia), as well as with priority areas for the development of science and technology in the Russian Federation.

China and Russia have more than 400 years of history of relations, during this period both countries have built a solid political, economic, and social foundation.

The establishment of diplomatic relations between China and Russia will soon exceed 70 years. In 2006, China held the Year of Russia, and in 2007, Russia held the Year of China. Then, in 2009, China had the Year of the Russian Language, and in 2010, Russia had the Year of the Chinese Language. The organization of such events is another important step towards strengthening the China-Russian friendship from generation to generation 
and promoting bilateral relations of strategic interaction and partnership.

In the context of expanding contacts with foreign countries, the role of Yakutia has increased. Economic and political ties between Yakutia and China are currently constantly developing and strengthening. The Chairman of the State Assembly of the Republic of Sakha (Yakutia) Alexey Eremeev, speaking on July 13, 2021, at a meeting dedicated to interregional RussianChinese economic and cultural ties, put forward proposals regarding scientific and technical cooperation and investment cooperation. At the end of his speech, the Chairman of the State Assembly (Il Tumen) emphasized: "Today, the Republic of Sakha (Yakutia) certainly has a huge potential for expanding cooperation with the People's Republic of China in all sectors: in the economy and agriculture, science and technology, tourism and the development of intercultural relations.

\section{Results and Discussion}

This research is devoted to the study of the phonetic features of teaching Chinese to students of the Institute of Languages and Culture of the Peoples of the NorthEast of the Russian Federation. The phonetic, grammatical, hieroglyphic, and lexical features of teaching the Chinese language have been studied. The teaching material is of paramount importance in teaching Chinese. Chinese language students are Yakuts, and their main language of communication is the Yakut language. For these students, learning is based on a comparison of the native language and the target language. It should be noted that students, whose native language is the Yakut language, learn the grammar of the Chinese language easier, due to the similarity of the grammatical structure of the Yakut and Chinese languages.

It is important that at lectures and in practical classes, students should not be engaged only in memorizing the material but should acquire communication skills. Today a huge amount of research has been devoted to the formation of students' communicative competence. We also note that when teaching the Chinese language, it is necessary to take into account the specifics of the discipline in order to achieve the main goal - the mastery by students of the main types of speech activity in the Chinese language and always remember that the educational process should be aimed at the upbringing, education and all-round development of the student, the future teachers, using the Chinese language as an academic subject, to familiarize students with the culture of the Chinese people.

Teaching students the Chinese language includes mastering the main types of speech activity in the target language: listening, speaking, reading, writing. Based on this, four types of speech activity should be interconnected in each lesson:

1. Exercises and tasks in listening and listening comprehension (in listening).

2. Exercises and creative tasks in speaking, which are divided into exercises in dialogical speech and exercises in monologue speech.
3. Reading tasks.

4. Tasks in a letter.

Teaching of speech activity is basic in teaching a foreign language. For the successful performance of speech activity, first, the necessary language skills must be formed - phonetic, lexical, and grammatical. It is important to note here that active knowledge of a foreign language requires absolute knowledge of the phonetics of this language, 50-90\% - knowledge of grammar. There are three approaches to teaching the phonetics of the Chinese language: articulatory (phonological), acoustic and differentiated. The object of the study of the phonological approach is the natural matter of the human language - the sounds of speech. In the acoustical approach, the emphasis is on the auditory perception of speech and its imitation. The main exercise of this approach is to repeat or imitate the sounds heard. A differentiated approach involves the use of different analyzers to form a holistic phonetic skill. As with the acoustic approach, there is a lot of emphasis on listening. Dialogic speech and monologue speech plays a major role in the formation of speech skills. Based on the communicative function of the language, the dialogue should be considered the main and initial one: the monologue is usually always preceded by a dialogue.

The system of tasks in the dialogue should be aimed at teaching students not only questions and answers, but also at composing responses, at exchanging opinions, at picking up on the interlocutor's thoughts: a reaction to what he heard and phrases that encourage the interlocutor to continue the conversation.

The system of exercises in teaching dialogue should be in a certain sequence:

a) receptive (listening and understanding the dialogical pattern).

b) reproductive (reproduction of a dialogical sample at different levels, by imitation from memory, etc.).

c) constructive (the stage of relatively free speech with an orientation towards the ratio of the learned dialogical patterns to the new situation). In the methodology, a monologue is understood as a form of speech, which consists of several speech units expressed by the same person to communicate information of varying complexity and volume. Unlike dialogue, which allows for "discontinuity" of statements, pauses and even silence (when the interlocutor nods his head), the monologue is continuous, because the formation of thoughts here occurs simultaneously with the process of speaking (of course if we are talking about an unprepared statement).

In our conditions, with an insufficient volume of oral speech practice, in particular Chinese, reading remains a more accessible speech skill. The main goal of reading is to improve the technique of reading in the target language and understanding the content of what is being read, i.e., extraction of new information.

One of the main tasks of a teacher of the Chinese language is to teach students to read the language consciously, and this, in turn, depends on the vocabulary available to students and their knowledge of grammatical forms and structures. For students to be able to 
independently read (and understand) Chinese texts, it is necessary to provide Chinese-Russian dictionaries.

Written speech also serves as a target skill. The student must be accustomed to permanently fixing the material. The work on teaching writing consists of tasks and exercises both for working out the writing technique (graphics, spelling and punctuation) and for teaching productive writing, for instilling the skills and abilities of students to express their thoughts in Chinese in writing. Before starting to study the sounds of Chinese speech, the teacher should familiarize students with the differences between the sounds of the Yakut and Chinese languages, as well as show which speech organs are involved in pronouncing the sound, and in what position they are. Students need to be given a clear idea of the sound itself and how it is pronounced, as this will contribute to the conscious and rapid mastery of pronunciation. It will be effective to use the schemes of the device of the speech apparatus when explaining the features of the articulation of Chinese sounds.

In Chinese classes, teachers most often use the International phonetic alphabet (IPA) - system of signs for recording transcription based on the Latin alphabet. It was developed and supported by the International Phonetic Association and is now actively used by both foreign language teachers and students, as well as linguists, speech therapists and translators.

One of the biggest difficulties that learners face when teaching the phonetics of the Chinese language is the process of mastering tones. First of all, the teacher needs to explain to the students the importance of the role of tone in the Chinese language, tell what types of tones there are and their characteristics. It is recommended to acquaint in more detail about each of the tones and its characteristic features in the process of studying a particular tone. Many Chinese textbooks are designed so that mastery of all four tones occurs simultaneously, and this practice is questioned by many methodologists. If students study several tones at the same time, then they solve several complex problems, and this contradicts one of the main provisions of the methodology of teaching foreign languages - to solve only one complex problem. You also need to remember that the quality of the vowels also depends on the tone. The experience of teaching the Chinese language to different students and numerous methodological recommendations with students showed that the study of tones should take place in a certain sequence [5, 27].

You need to start the study of tones from the first, which is recommended to be best mastered on syllables, which are a combination of an initial consonant and a syllable vowel. For example, syllables with consonants $m, n$ and $f$ combined with vowels $a, u$ and $i$. Students master the first tone without any special problems, however, typical mistakes that are characteristic of the initial stage of training may occur. Students tend to lower the intonation of the first tone towards the end of the sound. The second typical mistake is the wrong beginning of pronunciation, which manifests itself in "sliding" to the initial level of the first tone from above or below, in other words, learners adjust to the tone. To avoid such a mistake, it is recommended that students demand an abrupt start of sounding, as if they were "pricking" the sound. After students get used to the first tone, they can pronounce more complex sounds and sound combinations. As soon as students master the first tone, it is recommended to move on to the study of the third tone, which is more contrasting than the first.

It is in the third tone that diphthongs and triphthongs are well absorbed, including combinations with end sonants. When setting this tone, it must be remembered that its beginning is the lowest level of the student's voice, since this part is the least intense and compensates for it by increasing the duration of the tone and the degree of muscle tension. There is a certain relationship between the intensity and duration of a tone: the more intense the tone, the shorter it is, and the lower the intensity of the tone, the more durable it is. It is believed that the third tone is learned better when students pronounce its ascending part sharply, as if with a leap, and not smoothly. It is recommended to learn in the third tone only descending diphthongs and some triphthongs, ascending diphthongs and the remaining triphthongs to study already in the fourth tone.

The difficulty that may arise when setting the second tone is associated with mastering the pitch of the initial level. Compared to the third tone, the second tone is short. Mastering the fourth tone in an isolated position occurs without any particular difficulties, but one must not forget to monitor the intensity of the beginning of its sounding and some pharyngealization (articulation during the pronunciation of sounds is accompanied by a narrowing of the larynx) of the end of the syllable.

When learning the tones of the Chinese language, it is imperative to pronounce it in an exaggerated way, as this will allow students to control their pronunciation and prevent the occurrence of errors associated with the direction of movement of the tones.

The main methodological problem of the formation of pronunciation skills, according to some methodologists of the Chinese language, is that the students have developed and consolidated the idea of the Chinese word as a single, indissoluble complex, which includes three components: the sound composition of the syllable, meaning and tone. It is strictly not recommended to give assignments where students will need to rewrite the words given in the hieroglyphic notation into the Latin alphabet and put tone signs over the syllables. The tone sign is an integral part of the phonetic notation of a syllable since it has a meaningful function in the Chinese language. Also, at the initial stage of teaching phonetics, you need to enter the Chinese phonetic alphabet "pinyin" - the romanization system for Mandarin - the official language in the People's Republic of China [4, 31-33].

A variety of phonetic exercises are required to master pronunciation skills. The basis of the set of such exercises is made up of imitative exercises on the principle of "listen, repeat, speak", where students first listen to the speech of the teacher or speaker, which is an exemplary pronunciation of the studied sound or syllable, and then each student must repeat the listened phonetic material following the sample. In addition, students need to constantly repeat the material learned out loud outside the classroom. However, imitative 
phonetic exercises are rather monotonous and, even, can be tedious, so the teacher needs to pause in the lesson, which can be filled with stories about the history and culture of China, as well as interesting facts about life in the Middle Kingdom. You can also diversify phonetics classes with various phonetic games at the initial stage of phonetics training.

Exercises from various complexes can be combined and combined with each other. For example, the study of basic vowel sounds takes place simultaneously with the study of the first tone, that is, the vowels are pronounced in the first tone, then the initial consonants are added to the vowels, and as a result, syllables are formed that are read in the same tone. After a series of sounds and the first tone have been mastered, students can be given a credit exercise, which can be presented in a playful way. In the process of mastering a number of sounds, sound combinations and tones, you can make a "cultural insert": this can be an exercise in reading a short excerpt from poems and tongue twisters, or singing light songs, which will not only help students to take a break, but also improve pronunciation, help master sociocultural competence.

Students whose native language is Yakut find it easier to learn Chinese against the background of similar phonetic features of the Yakut and Chinese languages. The main problems in learning Chinese at the initial stage are phonetics (pronunciation of sounds, syllables, tones) and writing. At first glance, Chinese hieroglyphs represent a complex system of chaotically scattered lines, and most of the sounds, like the "toning" of syllables, do not exist in the Yakut language. Even if a student masters the basic principles of the language, knows how to pronounce all sounds and tones correctly, writes hieroglyphs according to the rules of calligraphy, another problem arises - how to start speaking in Chinese, how to make sentences and texts correctly, and formulate your thoughts. One of the problems of learning the Chinese language is memorizing many elements in the composition of the hieroglyph. Many people use the method of associations, correlating a hieroglyph and / or its parts with a picture, image, object, or phenomenon. On the one hand, this method facilitates memorization, since often the first reaction of a person to new information is to correlate it with already received (old) knowledge. On the other hand, the method of associations often interferes, and sometimes even hurts in learning, because the student begins to replace the meaning of the hieroglyph with the association itself, which does not allow understanding the meaning of phrases, phraseological units and sentences. Most often, hieroglyphs are associated with everyday objects, with a person, his postures, and actions, with nature and natural phenomena. For example, the hieroglyph 目 with the meaning "eye, look" is associated with a staircase by many students; the hieroglyphs 木 ("tree") and 水 ("water") are perceived by them as the Russian letter Ж, and often students do not see any differences between these hieroglyphs; the hieroglyph $人$ is associated with a mountain or a roof, and many find it difficult to understand and remember that the meaning of this hieroglyph is "person". [1:4] Both languages contain diphthongs and nasal sonants, for example: in Chinese the diphthong "uo", in Yakut - "uo", diphthong "yue", in the Yakut language "Yө" are pronounced the same, the nasal sonant in Chinese is ng and the nasal consonant in the Yakut language " $\mathrm{H}$ " is also pronounced the same way. If we talk about the alphabet, then in the Yakut language it is, but in the Chinese it is not. The Yakut alphabet contains 40 letters, while the Chinese phonetics is based on syllables. Each syllable can be divided into two parts. The initial sound is the initial and the final sound is the final. Some syllables contain only the initial, others only the final. There are 21 initials and 35 finals in Chinese. The ending contains at least one vowel. And, besides this, there are 5 more special syllables. A total of 56 basic sounds are obtained. Initials and finals plus special syllables give 411 possible syllable combinations. Chinese is a tonal language, and it follows that the meaning of a word changes depending on the intonation of the speaker. Yakut language differs in intonation among its speakers.

\section{Conclusion}

Learning any foreign language is a rather difficult process that requires a lot of time, effort, and resources. To communicate freely in another language, you need to master the phonetic base of a foreign language, which will help students understand the speech of native speakers and enter dialogue with them. However, at the initial stage of learning the Chinese language, the students face several difficulties that are associated with the peculiarities of the Chinese phonetic system.

Before starting to study the phonetics of the Chinese language, the teacher needs to explain to the students that the pronunciation methods that have developed in this language differ from the pronunciation methods in the Yakut language, and this should be reminded as often as possible. It is advisable in the classroom to immediately introduce such a system for recording hieroglyphs as "pinyin", and when explaining the peculiarities of articulation of Chinese sounds, use various schemes of the device of the vocal apparatus. Sounds, sound combinations, and tones are recommended to be studied in the sequence determined by the methodologists and teachers of the Chinese language who have extensive teaching experience.

To master phonetic skills, students are required to perform a variety of phonetic exercises in which students practice the skills of pronouncing Chinese sounds, sound combinations and tones. However, phonetics classes need to be varied, so it is recommended to include game exercises in the complex, as well as a number of exercises with an intercultural aspect, which will acquaint students with the elements of the culture of the language being studied.

Before starting to study vocabulary, grammar and other aspects of the language, the teacher is recommended to focus on teaching only one aspect for a while phonetics. Only after the learners have completely freed themselves from the pronunciation habits of their native 
language, and the movements of the speech organs when pronouncing Chinese sounds become familiar and will be performed with a minimum of conscious control, can one begin to study other aspects of the language.

Having cited all the examples and based on the works of scientists, teachers should conclude that the study of Chinese as a foreign language consists of three components - grammar, vocabulary and, of course, phonetics. Phonetics, in turn, is the most important component of the language, and Chinese in particular. She has a huge impact on the study of Chinese by Yakut students. After all, incorrect pronunciation carries with it both grammatical errors and errors in the use of words. That is why the teacher needs to set a goal - to teach students to perfectly master the phonetics of the language being studied.

In this way, the proposed tasks, and exercises of comparative teaching of the Yakut and Chinese languages, being repeated many times, are effectively assimilated by students. The organization of a special series of exercises contributes to the simultaneous interconnected development of all types of speech activity.

\section{References}

1. N.V. Du. Chinese. Phonetics, hieroglyphics, oral themes. Beginner level: study guide. (Ural Federal University, Ekaterinburg, 2016)

2. A.N. Alexanin. Theoretical Phonetics of Chinese. (ACT: Vostok-Zapad, Moscow, 2006)

3. T.P. Zadoenko, Huang Shuin. Basic Chinese course. (VKN Publishing, Moscow, 2016)

4. I.V. Kochergin. Essays on Chinese linguodidactics. (Vostochnaya kniga, Moscow, 2021)

5. N.A. Speshnev. Introduction to the Chinese. Phonetics and spoken language. (KARO, SaintPetersburg, 2016)

6. G.A. Zakharova, S.V. Molukova. Theory and methods of introducing students to the literature of the peoples of Russia at the lessons of native literature of schools of the Republic of Sakha (Yakutia). (NEFU, Yakutsk, 2021)

7. G.A. Zakharova. Study of Yakut literature at school with Russian (native) language of instruction in the context of a dialogue of cultures. (NEFU, Yakutsk, 2013) 